\title{
TESTING THE DESIGN OF TECHNICAL SOLUTIONS FOR LIQUID HYDROCARBON WASTES FIRE DISPOSAL
}

\author{
Sergey V. Dolgov ${ }^{1,}$, , Ruslan A. Visloguzov ${ }^{2}$, Sergey A. Khaustov ${ }^{2}$, Roman B. Tabakaev $^{2}$, \\ and Anton N. Ermolaev ${ }^{3}$ \\ ${ }^{1}$ MUE «Teplosnabzhenie», 628606 Nizhnevartovsk, Russia \\ ${ }^{2}$ Tomsk Polytechnic University, 634050 Tomsk, Russia \\ ${ }^{3}$ Federal State budget institution of higher education "Tyumen industrial University», 625017 \\ Tyumen, Russia
}

\begin{abstract}
The relevance of the work is caused by the need to develop the environmentally friendly heat-generating devices for disposal liquid technological wastes. The main aim of the research is to optimize the constructive implementation of technical solutions for disposal liquid hydrocarbon wastes. Using the software package «Ansys Multiphysics» the authors have simulated the combustion front at various flow conditions and measured reaction rate, temperature and components concentrations in the combustion zone. The results of the investigation have shown that the proposed technical solution has a number of features.
\end{abstract}

\section{Introduction}

The problem of the man-made liquid wastes disposal is one of the priority tasks to be solved by the international community. Liquid wastes are produced by oil refineries, chemical industry and transport, and may contain more than 200 dangerous chemicals causing irreparable harm to humans and the environment. This type of wastes contains large amounts of pollutants, harming to environment even when stored in specially engineered landfills. The magnitude of the problem is obvious, because in the most environmentally-advanced countries the proportion of the recycled wastes does not exceed $60 \%$, resulting in accumulation of wastes in large amounts.

Hundreds of millions of tons of sludge are accumulated, and 2-7.7 millions of tons of used lubricants are produced annually [1]. The possible ways of recycling can be divided into four main areas: dumping, recovery, recycling [2-4] and fire disposal [5, 6]. But only 15 percent of the total amount of wastes are recycled [1].

The most promising areas are fire disposal or recycling into a new kind of product. Fire disposal can withal solve the problem of power supply of remote regions [7, 8]. At present power supply in these areas is provided by expensive imported diesel fuel [7,9].

Accordingly, development of the technical solutions for fire utilization of liquid hydrocarbon wastes and use of the produced energy is an important task of research.

\footnotetext{
*Corresponding author: tabakaevrb@tpu.ru
} 


\section{Fire disposal of liquid hydrocarbon waste in porous media}

The main problems of the liquid wastes fire disposing are explosion and environmental safety of the combustion [10]. The possible option of solving these problems above is the combustion of liquid hydrocarbons wastes in the porous layer. The flameless combustion for radiative heat release makes possible the reduction of temperatures in the combustion zone to the values lower then thermal threshold of nitric oxide [11, 12].

Previously, with the participation of the authors the burner design modifications for fire disposal of liquid fuels [13] have been developed, using kerosene TS-1 and the mixture of waste flammable liquids. Physical research of the developed models was performed on experimental stands. Structures, actions and methods of these tests are described previously in [13].

A review of studies made using the mathematical models [14], and the analysis of experimental results suggest that all examined burners require a high excess air ratio (EAR $=2-6$ ) because of the low mixing speed in the porous layer for complete fuel oxidation process. Reducing the excess air ratio results in excessive levels for unburnt fuel, causing burner to operate in "environmentally unfriendly" flare mode that uses the diffusion of atmospheric oxygen $[5,6]$. Organization of the combustion with the high values of EAR and aerodynamic resistance of the workspace requires additional energy consumption for blasting, and therefore it has limitations on the capacity when firing low-calorie waste liquid hydrocarbon.

The objective of this study is to study the characteristics and regularities of the combustion process in the porous layer to be used in the development of the design of the burner device for effective fire disposal of liquid wastes.

\section{The object and method of study}

Using the application software "Ansys Multiphysics" the mathematical modeling of the combustion front in different conditions was produced and detailed contours of total and static pressure, temperature and concentration of the components in the combustion zone were obtained. The initial data for mathematical modeling were geometric and operational parameters of the chosen burner. The study proposed a modernized system for fire disposal of liquid hydrocarbon wastes in the form of a heat generating unit (Fig. 1), where:

- a combustion chamber (2) is a hollow cylinder, which prevents leakages of the airfuel mixture through the chamber walls;

- an air injector (5) is formed with perforations along the entire length, ensuring the uniform air flow into the combustion chamber in both directions: from the center to the periphery and upwards;

- fuel injectors (4) are evenly spaced around the air injector, ensuring the uniform mixing of the oxidant (air) and fuel.

Considered technical solution is based on the combustion chamber (2), designed as a gas-tight, hollow, filled with chemically inert porous filler cylinder with the diameter of 57 $\mathrm{mm}$ and the height of $200 \mathrm{~mm}$. Front of the combustion is stabilized via portion of the porous filler (6) mounted on the fuel-flow path. An important initial condition for the mathematical modeling is the filler temperature higher than the fuel ignition temperature. During the study of variants with different values of this parameter it was determined that the convergence of the steady-state solutions of combustion and heat transfer equations can't be achieved with the initial temperature of the porous layer below the fuel ignition temperature. The autothermal combustion is concluded to be only possible in the case of 
preheating the porous medium above the fuel ignition temperature due to the thermal inertia of the porous filler in the investigated burner device. That glowing filler fraction is a source of ignition.

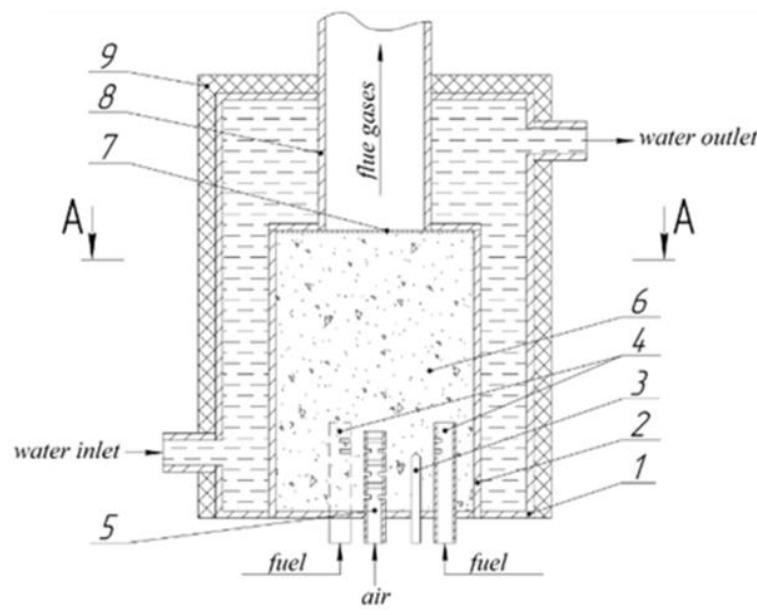

a

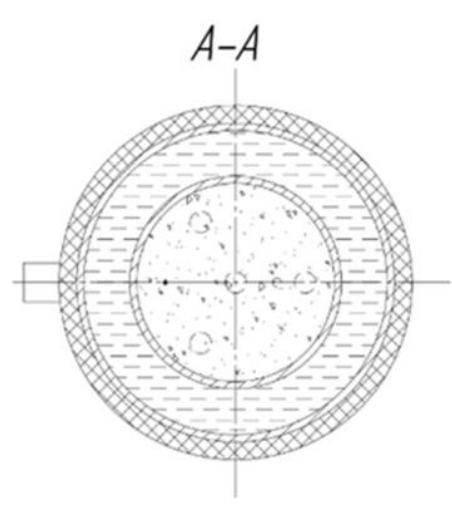

b

Fig.1. Longitudinal (a) and transverse (b) sections of a heat generating unit utilizing liquid hydrocarbon wastes: 1 is the casing; 2 is the combustion chamber; 3 is the ignition element; 4 are the fuel injectors; 5 is the air injector; 6 is the porous filler (carbon beads); 7 is the steel mesh nozzle; 8 is the channel for combustion products; 9 is the thermal insulation.

\section{Results of the study}
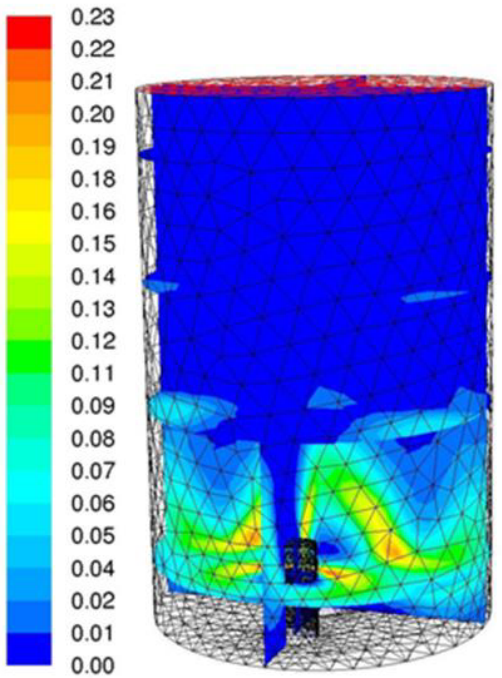

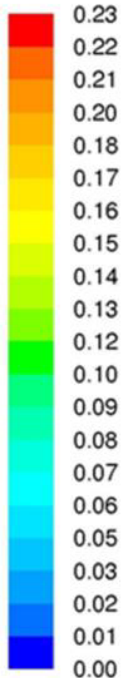

0.22

0.21

0.20

0.18

0.17

0.16

0.15

0.14

0.13

0.12

0.10

0.09

0.08

0.07

0.06

0.05

0.03

0.02

0.01

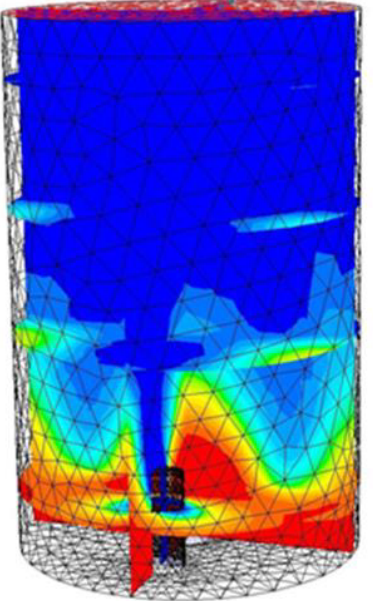

b

Fig. 2. Reaction rate contours, $\mathrm{kgmol} /(\mathrm{m} 3 \cdot \mathrm{s})$ (a) and the oxygen mass fraction, $\mathrm{kg} / \mathrm{kg}$ (b) in a longitudinal section of the combustion chamber.

Contours of the chemical reaction rate and the oxidant mass fraction (Fig. 2) allow to estimate the geometric dimensions of the reaction zone, highlight the areas of the kinetic and diffusion combustion. Liquid fuel moves in the layer of heated porous filler and 
vaporizes. The diffusion of the fuel jet into the air stream occurs on the external borders of the flame. The air-fuel mixture ignites forming the narrow angular combustion front, which burns less than $50 \%$ of the fuel. The highest values of the chemical reaction rate -200 $\mathrm{mol} /\left(\mathrm{m}^{3} \cdot \mathrm{s}\right)$ are observed near the fuel injectors. Further combustion occurs in the diffusive mode as mixing. The resulted combustion front occupies one third of the porous filler (Fig. 2a). Estimated average reaction rate value is $90 \mathrm{~mol} /\left(\mathrm{m}^{3} \cdot \mathrm{s}\right)$ in this region.

Despite the fact that the reaction zone is localized in the bottom of the combustion chamber, the temperature distribution on the combustion chamber volume is almost uniform due to the thermal conductivity in the porous layer (Fig. 3). It should be noted that the steady state values of the mean temperatures of the filler granules are equalized with the temperature of the surrounding flue gases.

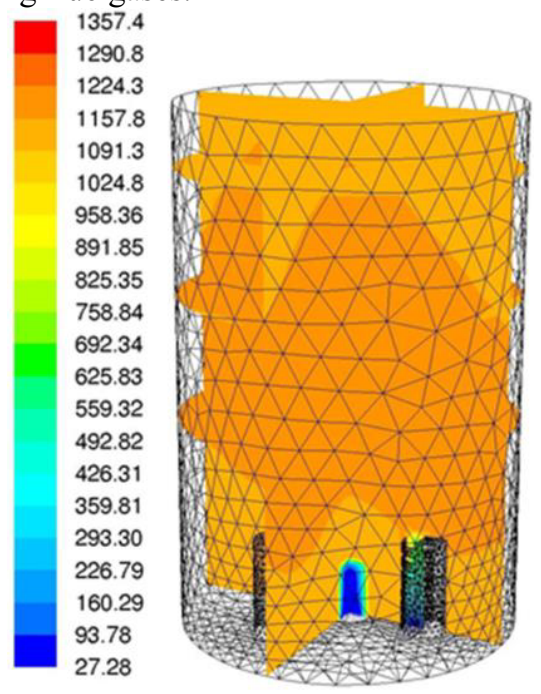

Fig. 3. Temperature contours $(\mathrm{K})$ in the longitudinal section of the combustion chamber.

The maximum temperature in the combustion zone $(1357 \mathrm{~K})$ is less than $1473 \mathrm{~K}$ - the threshold for thermal NOx nitrogen oxides formation $[17,18]$. In this regard, it can be argued that the combustion of liquid hydrocarbon wastes in this device will be accompanied by low emissions of harmful substances into the environment. away from the center the temperature is reduced down to $1036-1220 \mathrm{~K}$ in the wall region. Maximum of the emission spectrum (the infrared wavelength range with a length of 2377-2799 nm) is rated by Wien's displacement law at these temperatures. The radiation power calculated by the StefanBoltzmann law is $91.8 \mathrm{~kW} / \mathrm{m}^{2}$ with the mean average temperature of $1127 \mathrm{~K}$. Thus, the total area of the examined combustion chamber surface $\left(0.04 \mathrm{~m}^{2}\right)$ radiates $3.7 \mathrm{~kW}(61.7 \%$ of the total thermal power of the device). The portion of the convective heat carried away by the flue gases (the remaining $38.3 \%$ ) can be reduced by increasing the thickness of the porous layer complicating the regulation of the unit due to higher warm-up time. Therefore, water cooling [12] channel (fig. 1, pos. 8) is placed after the combustion chamber (pos. 1) in order to reduce heat loss with the exhaust gases.

\section{Conclusion}

The results of the mathematical modeling show that the proposed device for fire disposal of the liquid hydrocarbon wastes has a number of features.

- The high aerodynamic resistance of the porous filler causes a prevalence of the diffusion combustion. 
- The thermal inertia of the burning core makes a power control difficult and takes time for warming up the device and entering the autothermal mode.

- The uniform heat dissipation in the combustion chamber enables a useful heat removal using the heating surface (water jacket).

- The low temperatures in the reactor are the reduction factor for the emissions of nitrogen oxides and other harmful substances during the utilization of liquid hydrocarbon wastes.

A low thermal conductivity of the filler particles forming the thermally inertial core causes an intensive heat exchange of a fuel-air mixture with the porous medium. Thus, the temperature distribution becomes uniform in volume, and the reaction zone fills a large part of the combustion chamber. However, the prevalence of the diffusive combustion requires a large air excess and long cocurrent trajectories of fuel and oxidant flows in order to eliminate the unburned carbon.

This work was carried out with the financial support from the grant of the Russian Scientific Fond (project No. 16-38-50126) and the grant of the Ministry of education and science of The Russian Federation (Government Order No. 13.948.2014/K).

\section{References}

1. S. Barişçi, M.S. Öncel, International Journal of Green Energy, 11, 255 (2014).

2. A. V. Kazakov, R. B. Tabakaev, P. Y. Novoseltsev, A. V. Astafev, MATEC Web Conf., 19, 1014 (2014).

3. A. S. Zavorin, R. B. Tabakaev, P. Y. Novoseltsev, A. V. Astafev, MATEC Web Conf., 19, 1015 (2014).

4. R. B. Tabakaev, A. V. Kazakov, A. S. Zavorin, Solid Fuel Chem., 49, 5 , 267 (2015).

5. A. V. Kazakov, S. A. Khaustov, R. B. Tabakaev and Y. A. Belousova, IOP Conf. Series: Materials Science and Engineering, 124, 012110 (2016).

6. S. A. Khaustov, A. S. Zavorin, K. V. Buvakov, L. D. Kudryashova, A. V. Tshelkunova, EPJ Web Conf., 82, 1041 (2015).

7. S. A. Khaustov, A. V. Kazakov, G. A. Cherkashina, L. A. Sobinova, The European Physical Journal Conferences, 110, 01028 (2016).

8. I. I. Shanenkov, A. A. Sivkov, A. Ya. Pak, Yu. L. Kolganova, Advanced Materials Research, 1040, 813-818 (2014).

9. I. I. Shanenkov, A. Ya. Pak, A. A. Sivkov, Yu. L. Shanenkova, MATEC Web of Conf., 19, 01030 (2014).

10. Z. Arsenijević, Z. Grbavčić, B. Grbić, N. Radić, R. Garić-Grulović, S. Miletić, G. Savčić, B. Dordević, Journal of the Serbian Chemical Society, 75, 523-535 (2010).

11. K.A. Al-attab, J.C. Ho, Z.A. Zainal, Experimental Thermal and Fluid Science, 62, 1-8 (2015).

12. X.-R. Chen, X.-S. Li, Z.-Y. Chen, Y. Zhang, K.-F. Yan, Q.-N. Lv, Energies, 8, 12421255 (2015).

13. S. Dolgov, E. Savchenko, S. Khaustov, R. Tabakaev, A. Zavorin, EPJ Web of Conf., 110, 01074 (2016).

14. S. A. Khaustov, A. S. Zavorin, K. V. Buvakov, and V. A. Sheikin, EPJ Web Conf., 82, 1039 (2015). 